\title{
Dick Wursten, «Dear Doctor Bouchart, I am no Lutheran». A reassessment of Clément Marot's Epistle to «Monsieur Bouchart»
}

\section{Filippo Fassina}

\section{(2) OpenEdition \\ 1 Journals}

\section{Edizione digitale}

URL: http://journals.openedition.org/studifrancesi/6237

DOI: $10.4000 /$ studifrancesi.6237

ISSN: 2421-5856

\section{Editore}

Rosenberg \& Sellier

\section{Edizione cartacea}

Data di pubblicazione: 1 novembre 2010

Paginazione: 540

ISSN: 0039-2944

\section{Notizia bibliografica digitale}

Filippo Fassina, «Dick Wursten, «Dear Doctor Bouchart, I am no Lutheran». A reassessment of Clément Marot's Epistle to «Monsieur Bouchart»», Studi Francesi [Online], 162 (LIV | III) | 2010, online dal 30 novembre 2015, consultato il 09 janvier 2021. URL: http://journals.openedition.org/studifrancesi/6237 ; DOI: https://doi.org/10.4000/studifrancesi.6237

Questo documento è stato generato automaticamente il 9 janvier 2021.

\section{c) (†) $\odot$}

Studi Francesi è distribuita con Licenza Creative Commons Attribuzione - Non commerciale - Non opere derivate 4.0 Internazionale. 


\title{
Dick Wursten, «Dear Doctor Bouchart, I am no Lutheran». A reassessment of Clément Marot's Epistle to «Monsieur Bouchart»
}

\author{
Filippo Fassina
}

\section{NOTIZIA}

DICK WURSTEN, «Dear Doctor Bouchart, I am no Lutheran». A reassessment of Clément Marot's Epistle to «Monsieur Bouchart», «Bibliothèque d'Humanisme et Renaissance», LXX, 3 (2008), pp. 567-578.

1 Le cause dell'arresto di Marot nel 1526 sono tuttora incerte e l'accusa di aver infranto il digiuno è sembrata da sempre piuttosto debole. Viene qui proposta la tesi secondo la quale la reale motivazione sarebbe stata l'accusa di essere luterano. Nella lettera indirizzata a uno sconosciuto Monsieur Bouchard-di cui il testo viene trascritto integralmente - si legge infatti la difesa di Marot dall'accusa di luteranesimo, definita una semplice calunnia. L'A. si sofferma anche su alcuni punti poco chiari della vicenda, come l'identità di Bouchard, il luogo della prigionia di Marot e la realtà della corrispondenza fra i due eruditi. 